\title{
The relationship of enuresis nocturna and adenoid hypertrophy
}

\author{
Muhsin Balaban ${ }^{1}$, Alper Aktas ${ }^{2}$, Cuneyd Sevinc ${ }^{1}$, Ugur Yucetas ${ }^{3}$ \\ ${ }^{1}$ Medicana International Istanbul Hospital, Urology Clinic, Istanbul, Turkey; \\ ${ }^{2}$ Kartal Training and Research Hospital, Urology Clinic, Istanbul, Turkey; \\ ${ }^{3}$ Istanbul Training and Research Hospital, Urology Clinic, Istanbul, Turkey.
}

\begin{abstract}
Summary Objectives: This study was organized to assess the relationship of enuresis noctur$n a(E N)$ and upper airway obstruction (UAO) in children. Material and Methods: This study was multi-centrically and prospectively designed including 79 children who presented to a urology clinic with symptoms of EN between January 2013 and February 2014. Sixty-four age-matched children with no history of urological complaints were randomly recruited from children admitted to a pediatric clinic as a control group. All children and parents were asked to fill out a dysfunctional elimination syndrome (DES) questionnaire and children were examined by an ear, nose and throat (ENT) specialist to evaluate the UAO. Descriptive statistics, chisquare and Mann-Whitney-U tests were used to compare variables.

Results: The mean ages of the 79 children (48 male, 31 female) in the study group and the 64 children (41 male, 23 female) in the control group were 10.14+/-3.38 and 9.17+/2.85 , respectively. Family history of the study showed that $19 \%$ of the children's mothers, $10 \%$ of the children's fathers and $37 \%$ of the children's siblings had experienced EN.

There was a significant difference between the study and the control groups in terms of urge to urinate, bladder emptying, bowel symptoms and psychological stress. There was also a significant difference between rates of tonsillar hypertrophy and nasopharynx obstruction in the EN group $(p=0.009)$. Conclusion: In this study we found that half of the children with EN had tonsillar hypertrophy, which was significantly higher than in the control group. Further studies are needed to clarify the exact relationship between UAO and EN.
\end{abstract}

KEY WORDS: Adenoids; Enuresis; Tonsillar hypertrophy.

Submitted 5 November 2015; Accepted 5 December 2015

\section{INTRODUCTION}

Enuresis nocturna (EN) is a common childhood condition, present in approximately 5-7 million children in the United States. The prevalence of EN decreases with age, but the severity increases (1). It is reported in about $15-20 \%$ of 5 year olds, $5-7 \%$ of 10 year old, and $1-2 \%$ of 15 year old subjects, reaching a plateau of approximately $0.5-1 \%$ in adulthood.

EN occurs when a child is unable to suppress nocturnal bladder contraction. There have been several explana- tions related to the physiopathology of EN. It is caused by a hereditary delay in maturation of the somatic mechanisms such as reduction of nocturnal urine production, relaxation of the bladder during sleep hours and a normal arousal to a full bladder that prevents the child from bedwetting (2). Evidence suggests a possible association with sleep-disordered breathing. Several studies have reported a close relationship between obstructive sleep apnea (OSA) and EN (3). The most common cause of OSA in children is adenotonsillar hypertrophy, and therefore treatment of adenotonsillar hypertrophy is the treatment of choice for OSA (4). Children with upper airway obstruction have increased negative intrathoracic pressure as a result of increased inspiratory effort during sleep. The continual swing in intrathoracic pressure causes cardiac distension that can lead to release of atrial natriuretic peptide, triggering enuresis (5).

In the present study, we aimed to identify the prevalence of adenotonsillar hypertrophy and upper airway obstruction (UAO) in children with and without EN as well as investigate the risk factors associated with EN in children.

\section{MATERIAL AND METHODS}

This study was multi-centrically and prospectively designed including 79 non-obese children older than 5 years who presented to a urology clinic with symptoms of EN between January 2013 and February 2014. EN was considered to be present when it occurred in the frequent grade (3-6 times per month) or the almost always grade ( $>3$ times per week) (6). EN was defined in accordance with the International Children's Continence Society's standardized terminology (7). Parents were asked whether their children currently suffer from enuresis and whether they have ever had a dry period of at least six months in order to distinguish primary from secondary enuresis. Only primary EN patients were enrolled in the study. Sixty-four age-matched children with no history of urological complaints were randomly recruited from children admitted to a pediatric clinic as the control group.

All EN patients underwent a detailed urological evalua-

No conflict of interest declared. 
tion and a thorough clinical and neurological examination to rule out an organic etiology. Exclusion criteria were the presence of cerebral palsy, neuromuscular diseases or any underlying systemic diseases or acute infectious processes. Additional medical history was taken, including duration of illnesses and current therapies. All children and parents were asked to fill out a 35item questionnaire related to symptoms of dysfunctional elimination syndrome (DES) such as diurnal/nocturnal enuresis, voiding habits, urgency, frequency, squatting and bowel movements. The questionnaire consisted of two parts: the first part included 21 multiplechoice questions for the child while the second part consisted of 14 questions asked to the parents. Eight questions included in the first part were also directed to the parents to test whether the children could correctly express their complaints. This confirmed the children's accuracy in answering the questions and ability to understand the problem. The second part had six additional questions for the parents about the frequency of urinary tract infection, school performance and stressful events. Parents and children were requested to fill out the form completely. Ear, nose and throat (ENT) examination were done by an ENT surgeon to assess obvious hypertrophied adenoids and tonsils clinically.

Descriptive statistics, chi-square and Mann-Whitney-U tests were used to compare variables.

\section{Results}

The mean ages of the 79 children (48 male, 31 female) in the study group and the 64 children (41 male, 23 female) in the control group were 10.14+/-3.38 and $9.17+/-2.85$, respectively. Forty-one males in the study group and 33 males in the control group were circumcised. Thirty-three of the 79 children in the study group and 22 of the 64 children in the control group were at pubertal ages.

Family history of the study group showed that 19\% of the children's mothers, $10 \%$ of the children's fathers and $37 \%$ of children's siblings had experienced EN. According to first 9 questions about urgency symptoms in the DES questionnaire, the study group's score was 5.65+/-3.50 and the control group's score was $1.31+/-2.15$ ( $\mathrm{p}<$ 0.0001 ). The scores of bowel symptoms (DES questions $10-15)$ were $2.11+/-1.37$ for the study group and $1.61+/$ 1.52 for the control group $(\mathrm{p}<0.006)$. The scores of psychological stress (DES questions 30-31) were 3.02+/-0.88 in the study group and $2.30+/-0.87$ in the control group $(\mathrm{p}<0.0001)$. The total scores of the DES questionnaire were 33.24+7-11.97 in the study group and 13.02+/-8.83 in the control group $(\mathrm{p}<0.0001)$ (Table 1$)$. There was also a significant difference between tonsillar hypertrophy and nasopharynx obstruction in the EN group ( $p=0.009$ ) (Table 2). Of the $79 \mathrm{EN}$ patients, 46 (58.2\%) had mono-
Table 2.

Compare of groups according to tonsillar hypertrophy and upper airway obstruction.

\begin{tabular}{|lcc|c|}
\hline & Obstruction (+) & Obstruction $(-)$ & P \\
\hline Enuresis $(n=79)$ & 37 & 42 & \\
& $(47 \%)$ & $(53 \%)$ & \multirow{2}{*}{0.0009} \\
\cline { 1 - 3 } Control $(n=64)$ & 13 & 51 & \\
& $(20 \%)$ & $(80 \%)$ & \\
\hline
\end{tabular}

symptomatic enuresis (ME) whereas 33 of 79 (41.8\%) had nonmonosymptomatic enuresis (NME).

\section{Discussion}

EN is the involuntary loss of urine during the night in the absence of organic disease. It is a very common pediatric issue and the number of children who may suffer from this condition is estimated at $3.8 \%$ to $25 \%$. In contrast to the relatively high percentage seen among children, only $1 \%$ to $2 \%$ of adults suffer from this disorder. This difference is a result of the increasing number of children who spontaneously achieve nighttime bladder control. Current data suggest an annual healing rate of $15 \%(8)$.

EN can present as monosymptomatic enuresis (ME) or nonmonosymptomatic enuresis (NME); this classification should be done before any kind of therapy protocol is initiated due to different treatment approach. The most important criterion of ME is the absence of bladder dysfunction, whereas NME is defined by the concomitance of bladder dysfunction such as urge incontinence or dysfunctional voiding. True ME is found in less than onehalf of all cases of enuretic children (9). In our study, we 
applied a DES questionnaire to all study and control group members to evaluate EN and its related symptoms. In this questionnaire, urgency symptoms, bowel symptoms, obstructive symptoms, psychological stress, infection symptoms and hereditary factor were evaluated. We found that $33(41.8 \%)$ cases of enuretic children had ME whereas 46 (58.2\%) cases had NME.

The genitourinary tract and the gastrointestinal system are interdependent, sharing the same embryological origin, pelvic region and sacral innervations. Although children with voiding disturbances often present with bowel dysfunction, until recently this coexistence was considered coincidental. However, it is now accepted that dysfunction of emptying of both systems, in the absence of anatomical abnormality or neurological disease, are interrelated (10). Children with DES commonly complain of urinary incontinence, NME, recurrent urinary tract infections, extreme urgency to void and exceptional urinary frequency. The prevalence of DES in children free of urinary tract infection as been estimated to be $21 \%(11)$.

The exact etiology of nocturnal enuresis is multifactorial; however, ME has a significant correlation with hereditary factors, arousal problems, overnight polyuria and overactive detrusor activity. In our study, EN patients had significant family histories of enuresis, mostly in their siblings. OSA in children is characterized by prolonged partial upper airway obstruction and/or intermittent complete obstruction that disrupt normal ventilation during sleep and sleep patterns (12). Goldbart et al. suggested an OSA sufferer repeatedly slips from deep sleep to light sleep, and when this happens, the bladder sphincter relaxes, releasing urine (13).

Adults with OSA have been shown to have elevated atrial natriuretic peptide (ANP), decreased antidiuretic hormone (ADH) (14) and no normal decrease in nocturnal urinary output (15). OSA causes oxygen desaturation, which influences the normal secretion of $\mathrm{ADH}$, leading to the change in nocturnal urine volume. Normally the nocturnal secretion of ADH slows nighttime urine production and prevents nocturia; inappropriate secretion of ADH results in an inability to concentrate the urine, leading to excess urine secretion and bedwetting (16). There is a positive correlation between plasma ANP levels and the degree of change in intrathoracic pressure. This correlation may result from elevated preload and atrial volume caused by a more negative intrathoracic pressure, thus stimulating ANP production in OSA patients.

Foxman et al. demonstrated a higher occurrence of EN among children with OSA than reported in otherwise healthy pediatric patients (17). According to Weissbach et al., UAO in children is greatly associated with nocturnal enuresis (4). In contrast to previous studies, Aydin et al. did not find any association between adenoid hypertrophy and nocturnal enuresis (18).

The most common cause of OSA in children is adenotonsillar hypertrophy and UAO. Waleed et al. showed a relief of EN by removing the UAO which was the cause of OSA and also a reduction in the total and night urine volume and improvement in nocturnal oxygen desaturation (19). Firoozi et al. showed the complete resolution of
EN in $31-76 \%$ of OSA patients within months after tonsillectomy and/or adenoidectomy (T\&A) (20).

In this study, half of the EN children had UAO and tonsillar hypertrophy; this rate is significantly higher than that of the control group.

\section{Conclusion}

Children with EN have deep sleep and high arousal levels due to hypoxia caused by upper airway obstruction. This study showed that children with EN have more adenoid hypertrophy and UAO compared with the control group. Children with EN should be referred to ENT surgeons for possible UAO and tonsillar hypertrophy evaluation. Prospective controlled studies are needed to further clarify these issues and the possible effect of T\&A treatment on the EN.

\section{REFERENCES}

1. Yeung CK, Sreedhar B, Sihoe JD, et al. Differences in characteristics of nocturnal enuresis between children and adolescents: a critical appraisal from a large epidemiological study. BJU Int. 2006; 97:1069-73.

2. Hjalmas K. Nocturnal enuresis: basic fact and new horizons. Eur Urol 1993; 33 Suppl 3:53-57.

3. Brooks LJ, Topol HI. Enuresis in children with sleep apnea. J Pediatr. 2003; 142:515-8.

4. Weissbach A, Leiberman A, Tarasiuk A, et al. Adenotonsilectomy improves enuresis in children with obstructive sleep apnea ayndrome. Int J Pediatr Otorhinolaryngol. 2006; 70:1351-6.

5. Ritting S, Knudsen UB, Norgaard JP, et al. Diurnal variation of plasma atrial natriuretic peptide in normals and patients with enuresis nocturna. Scand J Clin Lab Invest. 1991; 51:209-17.

6. Hjalmas K, Arnold T, Bower W. Nocturnal enuresis an international evidence based management strategy. J Urol. 2004; 171:2545-61.

7. Neveus T, Von Gontard A, Hoebeke P, et al. The standardization of terminology of lower urinary tract function in children and adolescents: report from the Standardisation Committee of the International Children's Continence Society. J Urol. 2006; 176:314-24

8. Robson WL. Clinical practice. Evaluation and management of enuresis. N Engl J Med. 2009; 360:1429-1436.

9. Neveus T, Eggert P, Evans J, et al. Evaluation of and treatment for monosymptomatic enuresis: a standardization document from the International Children's Continence Society. J Urol. 2010; 183:441-447.

10. Feng WC and Churchill BM. Dysfunctional elimination syndrome in children without obvious spinal cord disease. Pediatr Clin North Am. 2001; 48:1489-504.

11. Shaikh N, Hoberman A, Wise B, et al. Dysfunctional elimination syndrome: is it related to urinary tract infection or vesicoureteric reflux. Diagnosed early in life? Pediatrics. 2003; 112:1134-7.

12. Rosen CL. Obstructive Sleep Apnea syndrome (OSAS) in children: diagnostic challanges. Sleep. 1996; 19:274-277.

13. Goldbart DA, Levitas A, Greenberg-Dotan S, et al. B-type natriuretic peptide and cardiovascular function in young children with apnea. Chest. 2010; 138:528-535. 
14. Krieger J, Follenius M, Sforza E, et al. Effects of treatment with nasal continues positive airway pressure on atrial natriuretic peptide and arginine vasopressin release during sleep in patients with obstructive sleep apnea. Clin Sci. 1991; 80:443-449.

15. Ichioka $M$, Hirata $Y$, Inase $N$, et al. Changes of circulating atrial natriuretic peptide and antidiuretic hormone in obstructive sleep apnea syndrome. Respiration 1992; 59:164-168.

16. Kaditis AG, Finder J, Alexopoulos EI, et al. Sleep-Disordered breathing in 3680 Greek children. Pediatr Pulmonol. 2004; 37:499-509.

17. Foxman B, Valdez RB, Brook RH. Childhood enuresis: preve- lance, perceived impact, and prescribed treatments. Pediatrics. 1986; 77:482-487.

18. Aydin S, Sanli A, Celebi O, et al. Prevelance of adenoid hypertrophy and nocturnal enuresis in primary school children in Istanbul, Turkey. Int Jof Pediatr Otorhinolaryngol. 2008; 72:665-668.

19. Waleed FE, Samia FA, Samar M. Impact of sleep-disordered breathing and its treatment on children with primary nocturnal enuresis Swiss Med Wkly. 2011; Jul 1;141:w13216.

20. Firoozi F, Batniji R, Aslan AR, et al. Resolution of diurnal incontinence and nocturnal enuresis after adenotonsillectomy in children. J Urol. 2006; 175:1885-8.

\section{Correspondence}

Muhsin Balaban, MD (Corresponding Author)

muhsinbalaban1980@yahoo.com

Cuneyd Sevinc, $M D$

cuneydsevinc@yahoo.com

Medicana International Istanbul Hospital, Urology Clinic, Yeni mah.,

Pegagaz Sok. Soyak Evreka:A5-44, Soganlik, Kartal

34880 Istanbul, Turkey

Alper Aktas, MD

dralperaktas@hotmail.com

Kartal Training and Research Hospital, Urology Clinic, Istanbul, Turkey

Ugur Yucetas, MD

dryucetas@yahoo.com

Istanbul Training and Research Hospital, Urology Clinic, Istanbul, Turkey 